\title{
Controlled release of human growth hormone fused with a human hybrid Fc fragment through a nanoporous polymer membranet
}

\author{
Eung-Sam Kim, $\ddagger^{\mathrm{a}}$ Do Soo Jang, ${ }^{\mathrm{b}}$ Seung Yun Yang, ${ }^{\mathrm{c}}$ Mi Nam Lee, ${ }^{\mathrm{d}}$ Kyeong Sik Jin, \\ Hyung Jin Cha, ${ }^{d}$ Jin Kon Kim, ${ }^{c}$ Young Chul Sung ${ }^{\text {bd }}$ and Kwan Yong Choi ${ }^{\text {*ad }}$
}

\begin{abstract}
Nanotechnology has been applied to the development of more effective and compatible drug delivery systems for therapeutic proteins. Human growth hormone $(\mathrm{hGH})$ was fused with a hybrid Fc fragment containing partial $\mathrm{Fc}$ domains of human $\operatorname{lgD}$ and $\operatorname{lgG}_{4}$ to produce a long-acting fusion protein. The fusion protein, hGH-hyFc, resulted in the increase of the hydrodynamic diameter (ca. $11 \mathrm{~nm}$ ) compared with the diameter (ca. $5 \mathrm{~nm}$ ) of the recombinant hGH. A diblock copolymer membrane with nanopores (average diameter of $14.3 \mathrm{~nm}$ ) exhibited a constant release rate of hGH-hyFc. The hGH-hyFc protein released in a controlled manner for one month was found to trigger the phosphorylation of Janus kinase 2 (JAK2) in human B lymphocyte and to exhibit an almost identical circular dichroism spectrum to that of the original hGH-hyFc, suggesting that the released fusion protein should maintain the functional and structural integrity of hGH. Thus, the nanoporous release device could be a potential delivery system for the long-term controlled release of therapeutic proteins fused with the hybrid Fc fragment.
\end{abstract}

Received 27th January 2013

Accepted 7th March 2013

DOI: $10.1039 / c 3 n r 00474 k$

www.rsc.org/nanoscale
For the sustained release of hGH, various depot systems such as microparticles, ${ }^{8,9}$ liposomes, ${ }^{10}$ hydrogels ${ }^{6,11}$ and implants ${ }^{12}$ have been developed. The natural or synthetic polymer like hyaluronic acid and poly-lactic glycolic acid could also encapsulate the therapeutic protein into microspheres. ${ }^{\mathbf{1 3 , 1 4}}$ The polymerbased depot systems have to overcome the possibility of denaturation of proteins due to the formulation in organic solvents or acidic environment even though the biodegradable polymers were compatible to the human body. The conformational stability of rhGH in the depot system is an essential determinant to maintain its biological activity and to minimize undesired immunogenicity, since the active form of hGH has a four-helix architecture. ${ }^{15}$ The aggregation of rhGH resulted in lower efficacy than its native monomeric form. ${ }^{\mathbf{1 6 , 1 7}}$ Thus, the solvent-free environment during formulation and storage would enhance the therapeutic outcome in the sustained release system for rhGH.

In order to extend the half-life of therapeutic proteins in the blood stream, they were genetically fused to the stabilizing peptide, $^{17}$ albumin or scaffold ${ }^{18}$ of antibody heavy chains ${ }^{19}$ without any other modification such as PEGylation or glycosylation, thereby improving their pharmacokinetic properties. As many strategies to enhance the serum-half life of therapeutic proteins have been implemented, more effective delivery systems are still needed to maximize their efficacy by controlling the release profile. We recently devised a strategy to extend the serum half-life by constructing a flexible hybrid Fc with partial regions of $\mathrm{IgG}_{4}$ and $\mathrm{IgD}$ and then fusing it with erythropoietin (EPO). ${ }^{20}$ $\mathrm{IgG}_{4}$ exhibited weaker binding affinity with $\mathrm{Fc} \gamma$ receptors or 
complement component $1 \mathrm{q}$ than $\mathrm{IgG}_{1}$, the most widely used human Fc molecules. ${ }^{21}$ The IgG $_{4}$ Fc could circumvent antibodydependent cellular cytotoxicity or complement-dependent cytotoxicity. ${ }^{22}$ Additionally, the IgD fragment region of the hybrid Fc contributed the flexibility of the EPO-conjugate. ${ }^{20}$

The recent advancements of nanotechnology have enabled many nanoporous systems made of polymer or silica to overcome the challenging hurdles in separation and delivery of biomolecules. ${ }^{23}$ Owing to the tunability of pore size, the nanoporous membrane derived from block copolymers has been exploited in the size-exclusive diffusion of target molecules and ultrafiltration. ${ }^{24}$ Among the synthetic nanoporous membranes, a thin film of block copolymers such as polystyrene-block-polymethylmethacrylate (PS- $b$-PMMA) having hexagonally packed nanochannels vertically oriented to the membrane surface was reproducibly prepared by our group for the filtration of viral particles, controlled release of therapeutic proteins, and detection of single-base mismatch in DNA. ${ }^{25-28}$

Here, we attempted to control the release rate of hGH fused with a hybrid Fc fragment of human antibody, hGH-hyFc, as schematically shown in Fig. 1(a), using the nanoporous copolymer membrane fabricated with PS- $b$-PMMA. As in the EPO-hyFc ${ }^{20}$ the upper part of the hybrid Fc of hGH-hyFc is from human IgD Fc, and its lower part is from human $\operatorname{IgG}_{4} \mathrm{Fc}$. The molecular size of hGH-hyFc was characterized by gel electrophoresis, dynamic light scattering, electron microscopy, and small-angle X-ray scattering. The diameter of ordered nanopores in the polymer membrane was adjusted to the hydrodynamic diameter of hGH-hyFc. The release profile of hGH-hyFc through the nanoporous polymer membrane for one month was quantitatively analyzed. The biological function of the released hGH-hyFc was also investigated in a human B cell line, IM-9. The release of hGH with a human hybrid Fc was found to be controlled by the nanoporous membrane which could be applied to the delivery system of therapeutic proteins with a constant release rate for a long period.

\section{Experimental}

\section{Proteins and chemicals}

Purified hGH-hyFc which was expressed in Chinese hamster ovary cells (CHO-DG44) was provided by Genexine, Inc. (Seoul, (a)

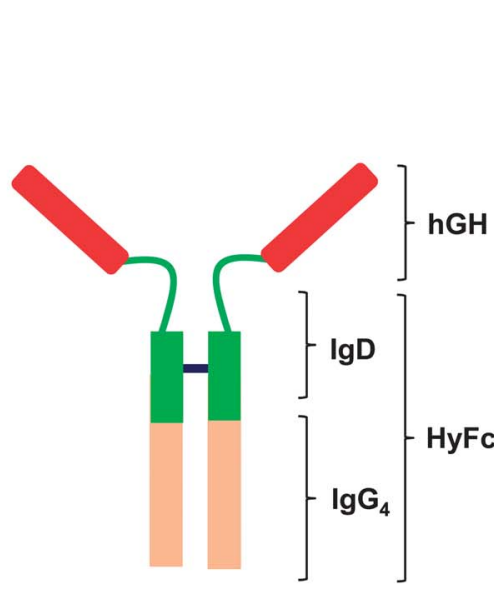

(c)

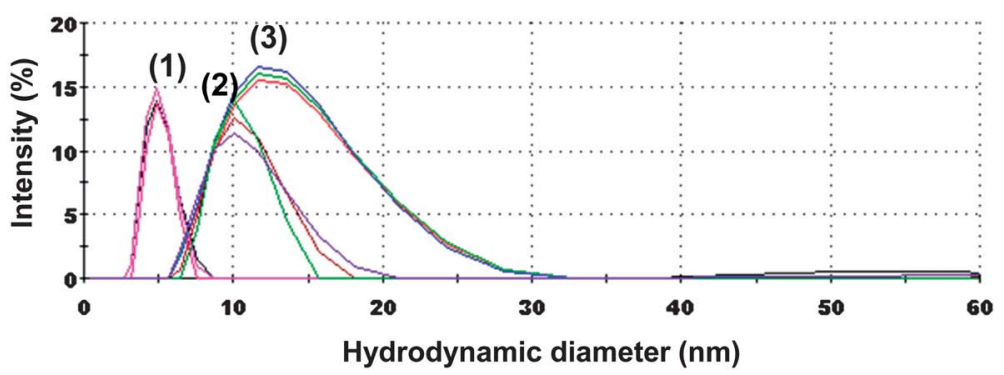

Fig. 1 Comparison of molecular sizes of rhGH, hGH-hyFc, and rat lgG by gel electrophoresis, immunoblotting and dynamic light scattering. (a) Schematic structure of a hGH-hyFc: hGH (in red) is fused to the hybrid human Fc which consists of the hinge region of the human IgD (in green) and the major $\mathrm{CH}_{2} / \mathrm{CH}_{3}$ domain of the human $\operatorname{lgG}_{4}$ (in yellow). The disulfide bond (in black) between cysteine residues in the individual hinge region of IgD induces the dimeric formation of $h G H$-hyFc. (b) $2 \mu \mathrm{g}$ of three proteins were respectively run on a $6-16 \%$ gradient polyacrylamide gel with the non-reducing loading buffer and stained with Coomassie Blue solution. The gradient gel containing $2 \mathrm{ng}$ of each protein was transferred to the nitrocellulose membrane for western blotting using anti-hGH antibody and the mixture of antimouse and anti-rat HRP-conjugated antibodies as a primary and secondary antibody, respectively. (c) The hydrodynamic diameters of three proteins in PBS were measured by dynamic light scattering using a $40 \mu \mathrm{l}$ cuvette. The peaks representing the mean hydrodynamic diameter were observed at 4.8, 10.5, and 13.3 for rhGH (1), hGH-hyFc (2), and IgG antibody (3), respectively. 
Korea). The purified hGH-hyFc was stored at $4{ }^{\circ} \mathrm{C}$ in a storage buffer (50 mM sodium phosphate, $15 \mathrm{mM} \mathrm{NaCl}, \mathrm{pH} 6.8$ at $25{ }^{\circ} \mathrm{C}$ ). The monoclonal rat anti-mouse IL-2 IgG $_{2 \mathrm{a}}$ antibody and non-glycosylated recombinant human growth hormone (rhGH) were obtained from BioLegend (San Diego, CA, USA) and Cell Sciences (Canton, MA, USA), respectively. All chemicals and solvents of reagent grade were purchased from Sigma-Aldrich (St. Louis, MO, USA), unless otherwise mentioned. All reagents were used without further purification. Ultra-pure water $(18.2 \times$ $10^{6} \Omega \mathrm{cm}$ ) for the preparation of aqueous solutions was supplied by a Milli-Q purification system (Millipore).

\section{Immunoblotting}

The rhGH, hGH-hyFc, and $\mathrm{IgG}_{2 \mathrm{a}}$ (Table S1 in the ESI $\dagger$ ) were separated in a $6-16 \%$ gradient SDS-polyacrylamide gel and transferred to a nitrocellulose membrane. The membrane was blocked by $4 \%$ (w/v) skimmed milk in a transfer buffer and then probed sequentially by an anti-hGH antibody (Santa Cruz) as a primary antibody and a horseradish peroxidase (HRP)-conjugated secondary antibody mixture containing goat anti-mouse and anti-rat IgGs (Zymed). The chemo-luminescence from the enzymatic reaction of peroxidase in the presence of an enhanced chemiluminescence solution (Thermo, Rockford, IL, USA) was detected by an X-ray film (Agfa, Belgium).

\section{Photon correlation spectroscopy}

The hydrodynamic diameters of rhGH, hGH-hyFc, and IgG antibody were determined by dynamic light scattering (DLS) using a Zetasizer Nano S (Malvern Instruments, UK). The proteins with a concentration of $1 \mathrm{mg} \mathrm{ml}^{-1}$ in $1 \times$ phosphate buffered saline solution (PBS, pH 7.4 at $25^{\circ} \mathrm{C}$ ) were loaded into a low-volume $(40 \mu \mathrm{l})$ quartz cuvette. The distribution of protein size was statistically represented by mean and standard deviation of three independent measurements. A single measurement consisted of thirty readings for scattering signals.

\section{Transmission electron microscopy}

hGH-hyFc (1 $\left.\mathrm{mg} \mathrm{ml}^{-1}\right)$ solution was desalted in a dialysis tube (D-tube, EMD Chemicals) for $6 \mathrm{~h}$ at room temperature and then mounted on a copper grid. The copper grid was dipped into the uranyl acetate $(0.5$ to $2 \%$ ) for $2 \mathrm{~s}$ and dried in air. Electron micrographs were recorded at $500000 \times$ magnification on a transmission electron microscope (JEM-1011, JEOL) at $80 \mathrm{kV}$.

\section{Small angle X-ray scattering (SAXS)}

X-ray scattering was carried out at the solution-scattering station set up at the $4 \mathrm{C} 1$ and $4 \mathrm{C} 2$ beam line at the Pohang Accelerator Laboratory (Pohang, Korea). The volume and path length of the sample cell were $50 \mu \mathrm{l}$ and $1 \mathrm{~mm}$, respectively. All measurements were performed at $25{ }^{\circ} \mathrm{C}$. The intensity of X-ray scattering in the small angle region was determined according to the equation reported previously: ${ }^{29} I(Q)=I(0) \exp \left(-R_{\mathrm{g}}{ }^{2} Q^{2} / 3\right)$, where $Q$ and $I(0)$ are the momentum transfer and intensity at $0^{\circ}$, respectively; $Q$ was defined by $Q=4 \pi \sin \theta / \lambda$, where $2 \theta$ and $\lambda$ are the angle between the incident $\mathrm{X}$-ray beam and the detector measuring the scattered intensity and wavelength of X-ray, respectively. The radius of gyration $\left(R_{\mathrm{g}}\right)$ was obtained from the slope of the Guinier plot $\left(\ln I(Q)\right.$ versus $\left.Q^{2}\right)$.

\section{Titanium reservoir with a nanoporous polymer membrane}

The nanoporous block copolymer membrane was fabricated as described previously. ${ }^{27}$ Briefly, the mixture of PS- $b$-PMMA and PMMA homopolymer in toluene was spin-coated on the silicon oxide layer of the silicon wafer and thermally annealed. To separate the polymer film from the wafer surface, the oxide layer was dissolved in the HF solution. The film was placed on the supporting membrane and was subjected to the generation of cylindrical nanopores by removing the PMMA homopolymer in the cylindrical PMMA block and swelling the PMMA block with acetic acid. The nanoporous membrane was dried under vacuum. The surface of the nanoporous polymer membrane was imaged using a field-emission scanning electron microscope (FE-SEM, Hitachi S-4600, Japan). For the titanium reservoir, its lower part was machined to have an inner diameter of $15 \mathrm{~mm}$ and a depth of $5 \mathrm{~mm}$. The outer surface of the lower part and the inner surface of the cover were screwed to fasten each other.

\section{Detection of released proteins}

The original solution of $1 \mathrm{mg} \mathrm{ml}^{-1} \mathrm{IgG}$ was diluted in sterilized PBS to the concentration of $500 \mu \mathrm{g} \mathrm{ml}^{-1}$. The hGH-hyFc which was supplemented with $1 \mathrm{mg} \mathrm{ml}^{-1}$ bovine serum albumin (BSA) for its stable long-term storage was diluted to $9000 \mathrm{ng} \mathrm{ml}^{-1}$. The protein solution was transferred to the lower part of the titanium reservoir. Prior to capping the cover, the circular membrane assembly of the supporting layer and the nanoporous polymer film was soaked in ethanol and deionized water sequentially. The wet membrane assembly was placed on the lower part of the titanium reservoir and the cover with a central hole was screwed. The titanium reservoir was immersed in a glass vessel containing PBS containing $0.1 \%$ BSA and the released protein was sampled at different time points. The sampled IgG antibodies were run on an $8 \%$ sodium dodecyl sulfate (SDS)-polyacrylamide gel and visualized by a silver staining kit (GE Healthcare). The released hGH-hyFc proteins that were sampled at different time points were run on an $8 \%$ SDS-polyacrylamide gel and visualized by immunoblotting with anti-hGH antibody (Santa Cruz) as a primary antibody and HRPconjugated goat anti-mouse IgG antibody (Zymed) as a secondary antibody.

\section{Enzyme-linked immunosorbent assay (ELISA) for hGH-hyFc}

For a sandwich-type ELISA (Fig. S1 in the ESI + ), the anti-hGH antibody raised in a goat was diluted in PBS to the final concentration of $5 \mu \mathrm{g} \mathrm{ml}{ }^{-1}$. $60 \mu \mathrm{l}$ of diluted antibody was incubated in each well of 8-well strips (Costar EIA/RIA strip, Corning) for $24 \mathrm{~h}$ at $4{ }^{\circ} \mathrm{C}$ followed by washing the wells with PBS containing $0.5 \%(\mathrm{v} / \mathrm{v})$ Tween 20 , PBST, three times to remove the unbound capture antibody. The well surface was blocked with $200 \mu \mathrm{l}$ of $1 \%(\mathrm{w} / \mathrm{v}) \mathrm{BSA}$ (Fraction V, Roche) in PBS for $1 \mathrm{~h}$ at $25^{\circ} \mathrm{C}$ and washed with PBST four times. The sampled solution for the 
fusion protein was incubated in the well for $1.5 \mathrm{~h}$ at $25{ }^{\circ} \mathrm{C}$ followed by washing four times with PBST. The HRP-conjugated anti-human IgG-Fc antibody (Bethyl Lab., TX, USA) as the detection antibody was diluted in PBS supplemented with $0.5 \%$ BSA to the final concentration of $50 \mathrm{ng} \mathrm{ml}{ }^{-1}$. The detection antibody was incubated in the well for $1.5 \mathrm{~h}$ at $25^{\circ} \mathrm{C}$ followed by washing five times with PBST. The chemo-luminescence signal was developed by adding $100 \mu \mathrm{l}$ of TMB solution (KPL, MD, USA), stopped by adding $100 \mu \mathrm{l}$ of $2.0 \mathrm{~N} \mathrm{H}_{2} \mathrm{SO}_{4}$, and read at $450 \mathrm{~nm}$ in the 96-well plate reader (TECAN).

\section{Circular dichroism (CD) spectroscopy}

CD spectra of hGH-hyFc were obtained using a spectropolarimeter (J-715, JASCO) at $20{ }^{\circ} \mathrm{C}$ under nitrogen. All scans from $250 \mathrm{~nm}$ to $200 \mathrm{~nm}$ for each sample in a quartz cuvette with $2 \mathrm{~mm}$ path length were done in triplicate. Raw data were acquired at $0.2 \mathrm{~nm}$ step size with $1 \mathrm{~s}$ response time. The residual ellipticity was obtained as an average of three scans and converted to molar ellipticity as described previously. ${ }^{30}$

\section{Immunoassay for detection of JAK2 phosphorylation in IM-9 cells}

IM-9 cells obtained from the Korean Cell Line Bank (http:// cellbank.snu.ac.kr) were cultured in the RPMI-1640 medium (GIBCO, USA) supplemented with $10 \%(\mathrm{v} / \mathrm{v})$ fetal bovine serum (FBS, Invitrogen, UK), $100 \mathrm{U} \mathrm{mL}^{-1}$ penicillin $\mathrm{G}$, and $100 \mu \mathrm{g}$ $\mathrm{mL}^{-1}$ streptomycin at $5 \% \mathrm{CO}_{2}$ and $37{ }^{\circ} \mathrm{C}$. Prior to treatment of rhGH and hGH-hyFc, cells $\left(2 \times 10^{6}\right.$ cells per $1.5 \mathrm{ml}$ in 6-well plate) were resuspended in RPMI-1640 medium supplemented with $0.5 \%$ FBS for $12 \mathrm{~h}$. Each protein of $1000 \mathrm{ng}$ was applied to the cells and the treated cells were harvested at different time points by centrifugation. The cells were solubilized in a cell lysis buffer containing $40 \mathrm{mM}$ HEPES, pH 7.5, 0.5\% Tx-100, $120 \mathrm{mM}$ $\mathrm{NaCl}, 1 \mathrm{mM}$ EDTA, $10 \mathrm{mM}$ pyrophosphate, $50 \mathrm{mM} \mathrm{NaF}, 1.5 \mathrm{mM}$ $\mathrm{Na}_{2} \mathrm{VO}_{3}, \quad 10 \mathrm{mM} \quad \beta$-glycerophosphate, $1 \mathrm{mM}$ phenylmethylsulfonyl fluoride, $5 \mathrm{mM} \mathrm{MgCl}$, and the protease inhibitor cocktail (Roche). The cell lysates were centrifuged at $15000 \mathrm{~g}$ for $30 \mathrm{~min}$ at $4{ }^{\circ} \mathrm{C}$ and supernatants were recovered. The phosphorylation of JAK2 was analyzed by SDS-PAGE and immunoblotting using the anti-phospho-JAK2 (Tyr1007/1008) antibody (Cell Signaling) and HRP-conjugated goat anti-rabbit IgG antibody (Jackson ImmunoResearch Lab.) as a primary and secondary antibody, respectively. The total amounts of JAK2 and actin were also monitored by the western blotting using antihuman JAK2 antibody (Cell Signaling) and anti-actin antibody (Santa Cruz) for the normalization of phosphorylation of JAK2 and the loading control of the cell lysate, respectively. The developed bands on the X-ray film were quantified with the NIH ImageJ program (available at http://rsbweb.nih.gov/ij/).

\section{Results and discussion}

\section{Characterization of hGH-hyFc fusion protein}

The molecular weight and specific affinity of hGH-hyFc were compared with those of rhGH and rat IgG antibody by gel electrophoresis and immunoblotting. The purified hGH-hyFc was homogeneous as judged by a single band of a $130 \mathrm{kDa}$ protein upon the PAGE analysis, while rhGH and rat IgG were found to be ca. $20 \mathrm{kDa}$ and $170 \mathrm{kDa}$, respectively (Fig. 1(b)). When hGHhyFc was treated with dithiothreitol (DTT) to reduce the disulfide bond between two Fc scaffolds, monomeric hGH-hyFc of $c a$. $55 \mathrm{kDa}$ could be separated (Fig. S2 in the ESI $\dagger$ ). Both dimeric and monomeric hGH-hyFc were found to have specific affinity to antihuman IgG and anti-hGH antibodies. The hydrodynamic diameters of rhGH, hGH-hyFc and IgG antibody in PBS were $4.8 \pm 0.9$, $10.5 \pm 2.1$, and $13.3 \pm 4.3 \mathrm{~nm}$ (mean $\pm \mathrm{SD}$ ), respectively, as measured by dynamic light scattering (Fig. 1(c)). The overall dimension of the dimeric hGH-hyFc was approximately $10 \mathrm{~nm}$ in width and $12 \mathrm{~nm}$ in height as determined by transmission electron microscopy (Fig. S2 in the ESI $\dagger$ ). The radii of gyration $\left(R_{\mathrm{g}}\right)$ of hGH-hyFc and rhGH were measured to be $4.69 \pm$ $0.0187 \mathrm{~nm}$ and $2.08 \pm 0.0083 \mathrm{~nm}$, respectively, by SAXS analysis.

Since hGH-hyFc is a fusion protein consisting of hGH and partial Fc fragments from human IgD and $\mathrm{IgG}_{4}$, its homodimeric molecular weight based on the amino acid sequence would be $c a$. $100 \mathrm{kDa}$. The glycosylation of hGH-hyFc in the $\mathrm{CHO}$ cell could account for the increase in its molecular weight as shown in the gel. The PNGase F treatment to cleave the bond between GlcNAc and asparagine yielded $3 \mathrm{kDa}$-smaller monomeric hGH-hyFc compared to the native one (Fig. S2 in the ESI $\dagger$ ). As we previously explored the overall structure of EPOhyFc using SAXS,${ }^{20}$ we also found that hGH-hyFc had a Y-shaped structure (Jang et al., unpublished data). In addition, hGH-hyFc could retain its molecular integrity for at least one month in the culture medium for IM-9 cells as monitored by SDS-PAGE and CD spectroscopy. The physical or structural transformation of hGH-hyFc such as fragmentation, nonspecific adsorption, dimerization or aggregation, which had been frequently observed in rhGH, ${ }^{31-33}$ was not exhibited for 30 days (Fig. S3 in the ESI + ). The unchanged antigen specificity against the antihGH antibody suggested that there should be no significant loss of activity as a ligand for its cellular receptors during this period. Thus, the hGH fused with human hybrid Fc domains was found to have the two-fold bigger hydrodynamic diameter and six-fold larger molecular weight than the native rhGH, retaining hGH activity and conformational stability under the culture conditions for at least one month.

\section{Controlled release of hGH-hyFc via nanoporous membranes}

Nanopores in the $80 \mathrm{~nm}$ thick polymer film fabricated by a selfassembling diblock copolymer, PS- $b$-PMMA, were found to be arranged in a self-ordered format as shown in Fig. 2(a) and 2(b). The diameter of nanopores and the center-to-center distance between two neighboring nanopores were $14.3 \pm 2.5$ and $36.2 \pm$ $4.1 \mathrm{~nm}$, respectively. The fraction of the area covered by nanopores on the surface of the polymer film was calculated to $c a$. $15 \%$. The titanium reservoir equipped with the nanoporous polymer membrane (Fig. S4 in the ESI $\dagger$ ) was employed to control the release of hGH-hyFc to the aqueous solution. As a control experiment, the rat IgG antibody with the initial concentration of $500 \mu \mathrm{g} \mathrm{ml} \mathrm{m}^{-1}$ was entrapped in the titanium reservoir and immersed in the PBS solution. The released IgG 
(a)

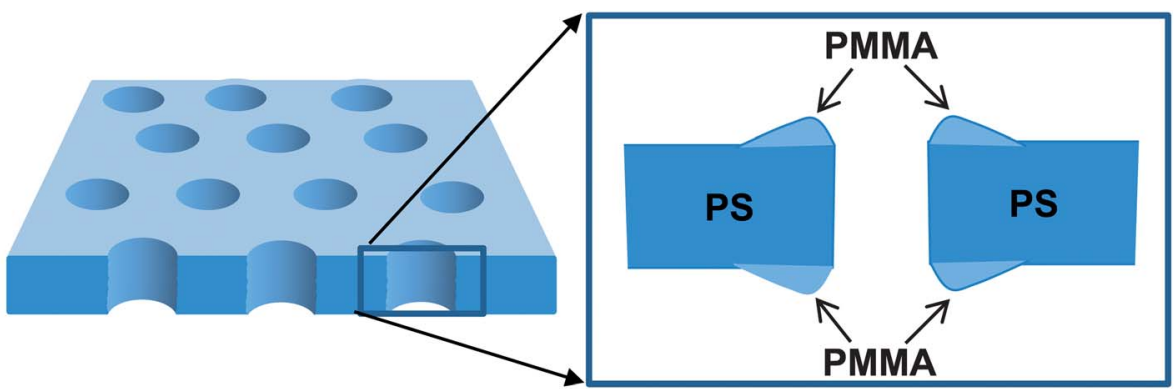

(b)

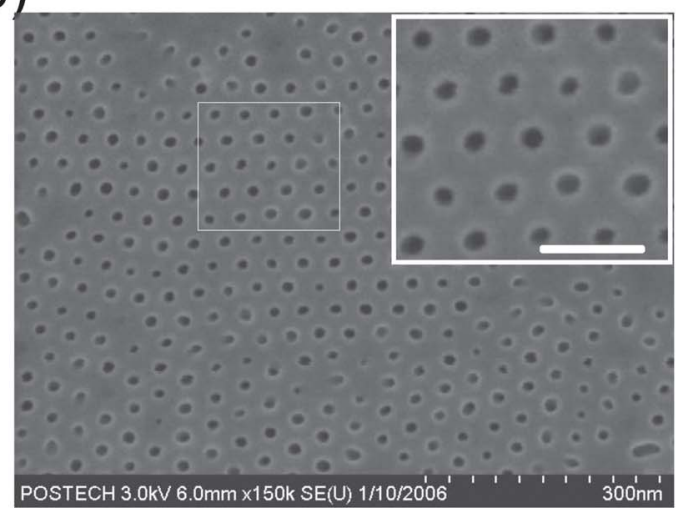

(c)

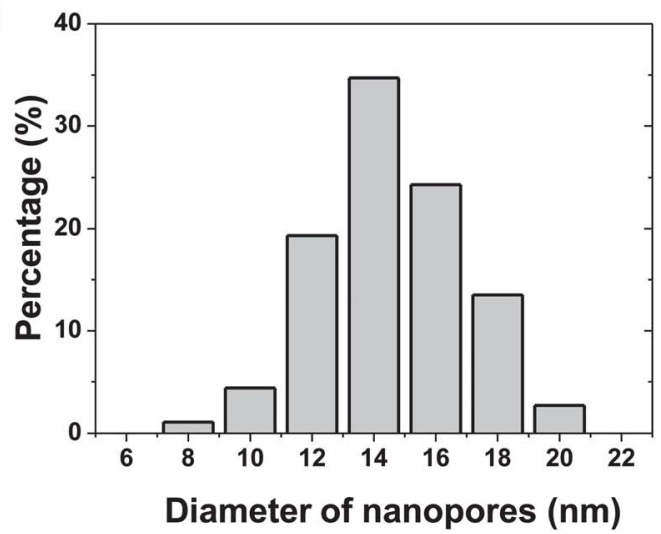

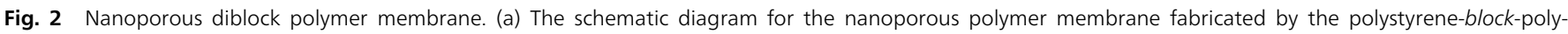

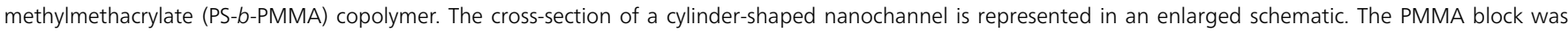

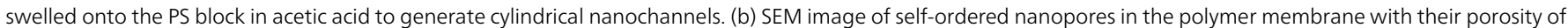

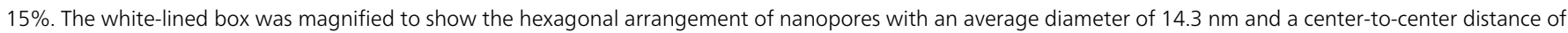

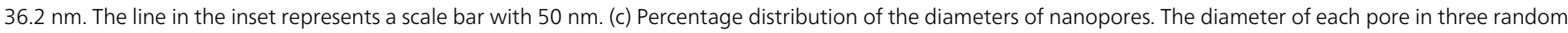
regions ( $1 \mu \mathrm{m} \times 1 \mu \mathrm{m}$ for each region) of the nanoporous membrane was measured.

antibody up to 14 days could be detected and quantified by silver staining after gel electrophoresis (Fig. S5 in the ESI $\dagger$ ). The rate of sustained release of IgG antibody was approximately $270 \mathrm{ng} \mathrm{h}^{-1}$ as estimated by the slope of the regression line.

When hGH-hyFc at the initial concentration of $1800 \mathrm{ng} \mathrm{ml}^{-1}$ or $9000 \mathrm{ng} \mathrm{ml}{ }^{-1}$ was released through cylindrical nanochannels of the nanoporous polymer membrane, the amount of released hGH-hyFc proteins was found to be proportional to the release time as evidenced by immunoblotting (Fig. 3). The rates of hGHhyFc release were estimated to be $4.4 \mathrm{ng} \mathrm{h}^{-1}$ and $22 \mathrm{ng} \mathrm{h}^{-1}$ for the initial concentrations of $1800 \mathrm{ng} \mathrm{ml}^{-1}$ and $9000 \mathrm{ng} \mathrm{ml} \mathrm{m}^{-1}$, respectively. The constant release of hGH-hyFc was sustained up to 25 days for the two different initial concentrations. The difference between the CD spectrum of hGH-hyFc released after 25 days and that of initial hGH-hyFc was negligible, suggesting that little conformational change was made along the controlled release. When the average diameter of nanopores was $27 \mathrm{~nm}$, the release rate was not constant over the 25 day long release (Fig. S6 in the ESI $\dagger$ ). Additionally the small nanopore with $7.4 \mathrm{~nm}$ in average diameter could hardly release hGHhyFc so that the total amount of released hGH-hyFc for 25 days was 43 -fold less than that of hGH-hyFc released through $14 \mathrm{~nm}$ diameter nanopores.

The constant release of hGH-hyFc without initial burst profile was achieved by the nanoporous polymer membrane with uniform diameter of nanopores. Since the ratio of the hydrodynamic diameter of hGH-hyFc to the average diameter of the nanopore was $c a .73 \%$, the diffusion-driven release of the fusion protein could be modeled to the single-file diffusion as described previously ${ }^{34}$ to explain the constant release of particles through the channel whose diameter is not two-fold larger than that of the particle. The gold deposition to the nanoporous polymer membrane was introduced to reduce the effective diameter of the nanopore to $6 \mathrm{~nm}$, resulting in the constant release profile of $\mathrm{rhGH}^{27}$ whose hydrodynamic diameter was $c a$. $4 \mathrm{~nm},{ }^{33}$ whereas the Fickian diffusion profile ${ }^{35}$ was observed in the bare nanoporous membrane with no gold deposition. The constant rate of controlled release of hGH-hyFc was dependent on the initial concentration in the reservoir. The rate of fourweek-long release was found to be proportional to the initial reservoir concentration. The spontaneous pore closing that could be encountered in the poly(lactic-co-glycolic acid) microsphere and hinder the controlled release of proteins ${ }^{36}$ was not observed in our nanoporous membrane after the one-month release. Additionally, the $80 \mathrm{~nm}$ long nanochannel did not cause any damage to hGH-hyFc, which might be accompanied by its conformational denaturation with reduced functional activity due to the random contact to the polymer surface during the one-dimensional diffusion in the nanochannel. The non-specific adsorption of the fusion protein on the surface of 
(a)

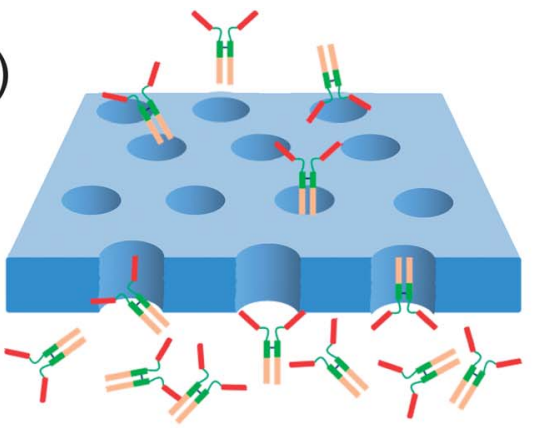

(c)

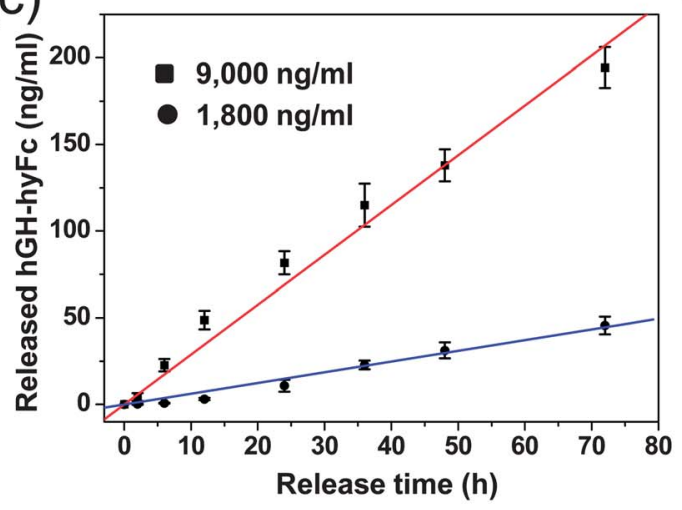

(b)

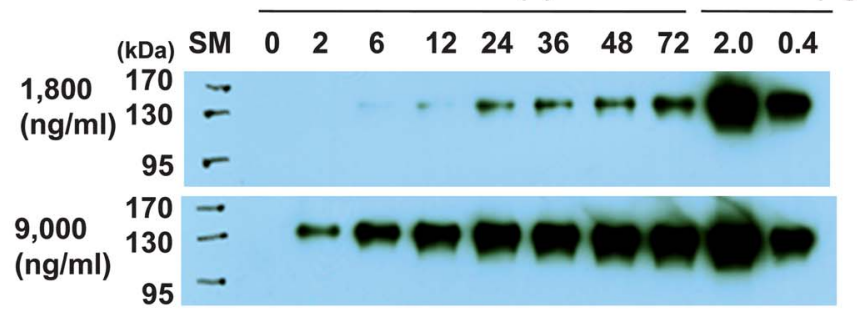

(d)

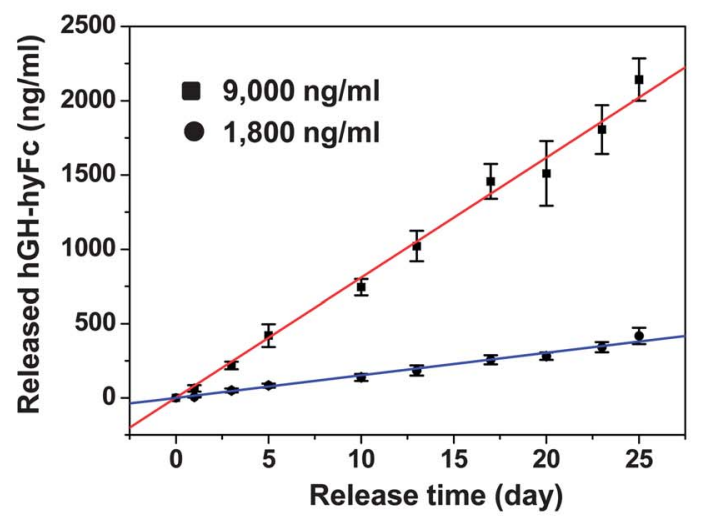

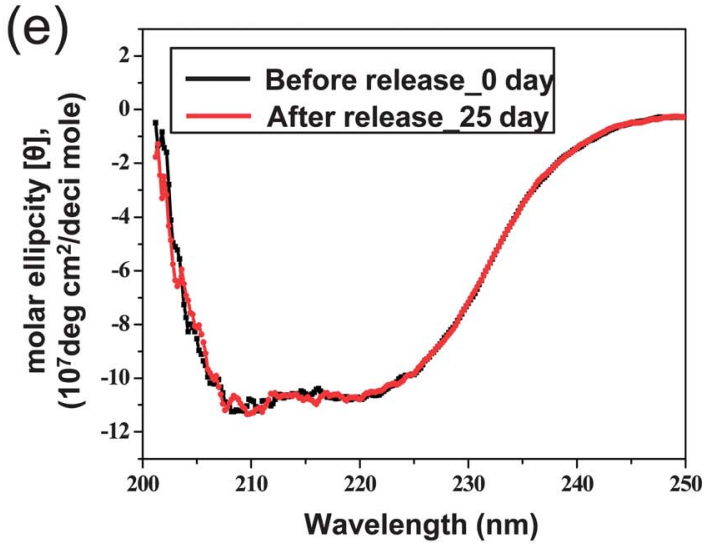

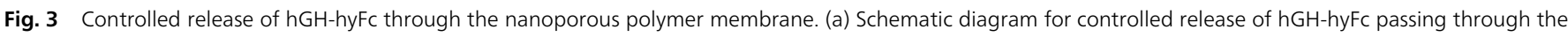

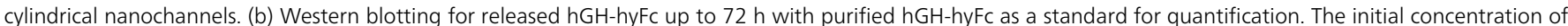

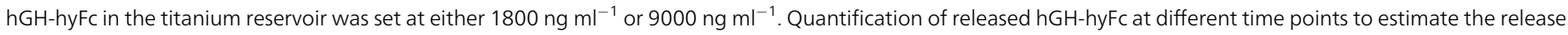

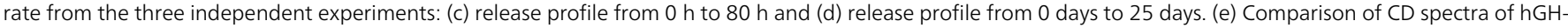
hyFc before and after the 25 day long release.

the nanoporous film or the supporting layer was negligible as judged by SEM images (Fig. S7 in the ESI $\dagger$ ). Therefore, we demonstrated the controlled release of functionally active hGHhyFc with an average hydrodynamic diameter of $11 \mathrm{~nm}$ through the polymer membrane with $14 \mathrm{~nm}$ nanopores.

\section{Signaling of released hGH-hyFc in human B cells}

The biological function of hGH-hyFc on human B cells was examined by the detection of phosphorylated-JAK2 (p-JAK2), since JAK2 was known to be a growth hormone receptor-associated tyrosine kinase ${ }^{37}$ Like rhGH, when hGH-hyFc was bound to the receptor on IM-9 cells, it could induce the phosphorylation of JAK2 (Fig. 4). The highest p-JAK2 level was observed at 5 min after the treatment of hGH-hyFc and rhGH, respectively. The p-JAK2 level was attenuated to the basal level at $60 \mathrm{~min}$ after the treatment. The amount of unbound hGH-hyFc proteins in the culture medium was assessed by ELISA after the removal of suspended cells by centrifugation. The initial concentration $\left(800 \mathrm{ng} \mathrm{ml}^{-1}\right)$ of hGH-hyFc was decreased to $250 \mathrm{ng} \mathrm{ml}^{-1}$ at $5 \mathrm{~min}$ in the presence of IM-9 cells and marginally decreased to $200 \mathrm{ng} \mathrm{ml}^{-1}$ up to 480 min whereas the protein level remained constant up to $480 \mathrm{~min}$ in the absence of cells. The concentration of free hGH-hyFc molecules in the culture medium was abruptly reduced within 

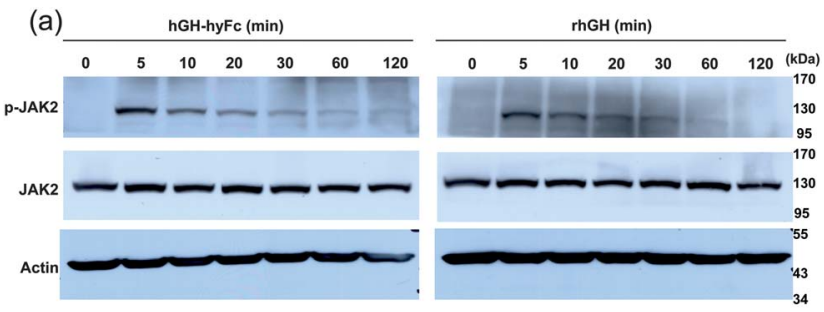

(b)

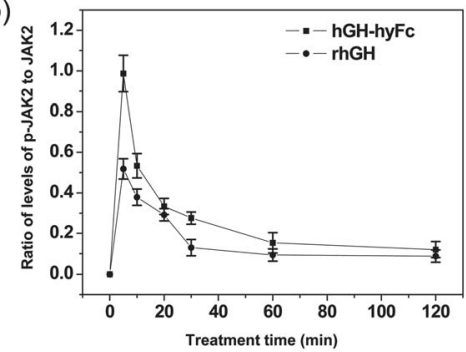

Fig. 4 Phosphorylation of JAK2 upon the treatment of IM-9 cells with rhGH and hGH-hyFc. (a) Levels of phosphorylated-JAK2 (p-JAK2) upon the treatment of IM9 cells with hGH-hyFc or hGH at the final concentration of $670 \mathrm{ng} \mathrm{m}^{-1}$. $\beta$-actin was used as a loading control. (b) Change of p-JAK2 levels normalized by JAK2 levels as a function of treatment time. The error bar represents the standard deviation from the three independent experiments.

5 min and no more significant change in the concentration of unbound hGH-hyFc molecules was observed after $5 \mathrm{~min}$. No fragmentation of the fusion protein was observed as judged by the immunoblotting analysis of hGH-hyFc. When IM-9 cells were treated with hGH-hyFc at different doses from 16 to $4000 \mathrm{ng}$ $\mathrm{ml}^{-1}$, the peak of tyrosine phosphorylation levels of JAK2 reached at $1000 \mathrm{ng} \mathrm{ml} \mathrm{m}^{-1}$ within $5 \mathrm{~min}$ of stimulation. The p-JAK2 level was decreased in the treatment of hGH-hyFc at the concentration higher than $2000 \mathrm{ng} \mathrm{ml}^{-1}$ (Fig. 5(a) and (b)). The hGH-hyFc that underwent the controlled release through the nanoporous membrane triggered the phosphorylation of JAK2, when the cells were suspended in the culture medium containing hGH-hyFc that was released for 25 days. The p-JAK2 level reached the peak in the 15 day long release medium and went down in the 25 day long release medium (Fig. 5(c) and (d)).

The homodimerization of hGH receptors is initiated by the interaction of hGH having two binding sites that are responsible for the engagement with a cell-surface receptor. The hGHmediated receptor dimerization is required for the tyrosine phosphorylation of JAK2 that is associated with each hGH receptor. The kinetic analysis of the JAK2 phosphorylation in response to the single treatment of $\mathrm{rhGH}$ and hGH-hyFc revealed that its rapid activation could peak within $5 \mathrm{~min}$ and be followed by the slow decrease to the deactivated state at $120 \mathrm{~min}$. When the number of hGH ligands supposed to participate in the receptor engagement was considered, the molar concentration of hGH ligands in hGH-hyFc containing two hGHs per molecule was 2.5-fold lower than that of rhGH under the same mass concentration. The higher ratios of p-JAK2 level to JAK2 levels supported the more effective signaling function of hGH-hyFc compared to that of rhGH. However, there seemed to be an optimum concentration of hGH-hyFc in IM-9 cells to trigger the tyrosine phosphorylation of JAK2 for a given number of cells. The mathematical model could explain the bell-shaped cellular response, showing an inhibitory effect on the receptor dimerization due to the high concentration hGH ligand. ${ }^{38}$ The concentration of unbound hGH-hyFc was decreased by $72 \%$ upon the treatment of IM-9 cells with hGH-hyFc while it was not

\section{(a)}

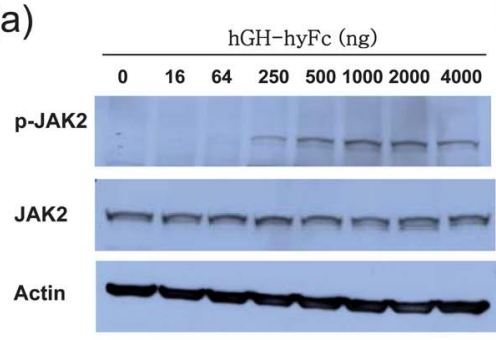

(c)

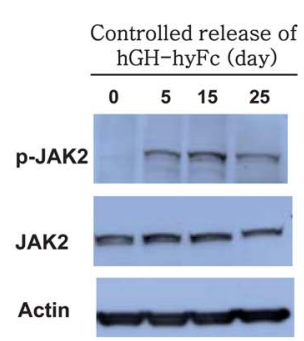

(d) (b)
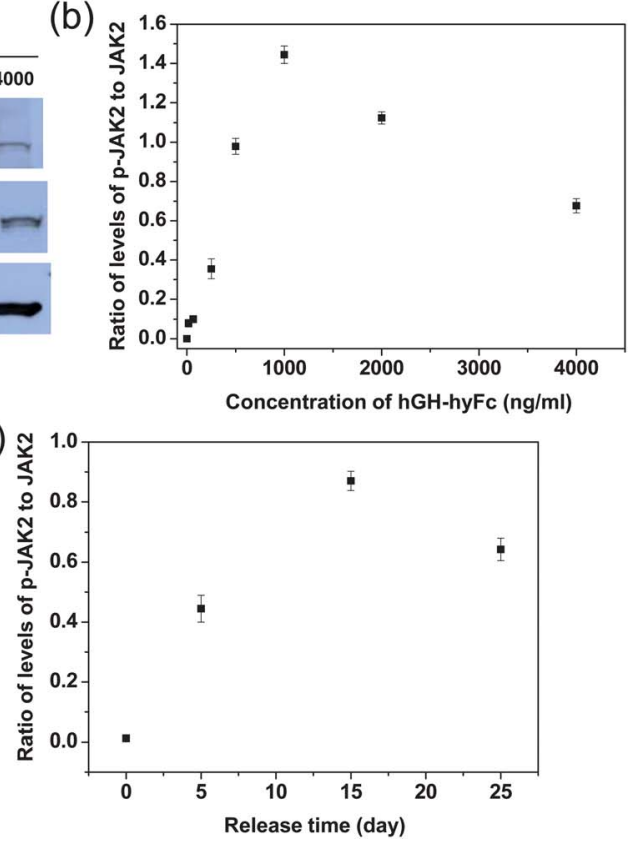

Fig. 5 Phosphorylation of JAK2 of IM-9 cells in response to released hGH-hyFc. (a) Change in p-JAK2 levels after the single 5 minute treatment of IM-9 cells with hGHhyFc. (b) Quantification of p-JAK2 levels normalized by the JAK2 level. (c) Phosphorylation of JAK2 of IM-9 cells that were exposed for 5 min to the culture medium with the hGH-hyFc released through the nanoporous membrane for 5, 15, and 25 days, respectively. (d) Ratio of p-JAK2 to JAK2 levels in response to released hGH-hyFc. 
in the absence of IM- 9 cells up to $2 \mathrm{~h}$, suggesting that hGH-hyFc released through the nanoporous membrane could activate IM-9 cells to induce the phosphorylation of JAK2 when the released fusion protein was treated with the inactivated cell.

\section{Conclusions}

We demonstrated the controlled release of hGH-hyFc, a longacting hGH using the nanoporous polymer membrane in a titanium reservoir. The fusion of hGH with the hybrid antibody Fc fragment originated from $\mathrm{IgD}$ and $\mathrm{IgG}_{4}$ was found to be stable in the cell culture medium and hGH-hyFc was able to activate JAK2 signaling more effectively compared with the recombinant hGH. The nanoporous polymer membrane made of the diblock copolymer was proven to be an efficient delivery system of hGH-hyFc with a larger hydrodynamic diameter than the unmodified hGH, exhibiting a constant release rate for at least one month. The released hGH-hyFc showing conformational stability could trigger the cellular response. The combined strategy to release the long-acting therapeutic protein with a hybrid Fc through the nanoporous membrane has a potential to be developed into a long-term drug delivery system.

\section{Acknowledgements}

This research was supported by the Next-Generation BioGreen 21 Program (No. PJ009503) of Rural Development Administration, Republic of Korea. This work was also supported by the National Creative Research Initiative Program of the National Research Foundation of Korea.

\section{References}

1 J. Leger, C. Garel, A. Fjellestad-Paulsen, M. Hassan and P. Czernichow, J. Clin. Endocrinol. Metab., 1998, 83, 3512-3516. 2 V. Petkovic, A. Besson, M. Thevis, D. Lochmatter, A. Eble, C. E. Fluck and P. E. Mullis, J. Clin. Endocrinol. Metab., 2007, 92, 2893-2901.

3 D. Rudman, A. G. Feller, H. S. Nagraj, G. A. Gergans, P. Y. Lalitha, A. F. Goldberg, R. A. Schlenker, L. Cohn, I. W. Rudman and D. E. Mattson, N. Engl. J. Med., 1990, 323, 1-6.

4 K. Mulligan, C. Grunfeld, M. K. Hellerstein, R. A. Neese and M. Schambelan, J. Clin. Endocrinol. Metab., 1993, 77, 956-962.

5 L. J. Woodhouse, A. Mukherjee, S. M. Shalet and S. Ezzat, Endocr. Rev., 2006, 27, 287-317.

6 S. Chen and J. Singh, Int. J. Pharm., 2008, 352, 58-65.

7 F. Fares, R. Guy, A. Bar-Ilan, Y. Felikman and E. Fima, Endocrinology, 2010, 151, 4410-4417.

8 O. L. Johnson, J. L. Cleland, H. J. Lee, M. Charnis, E. Duenas, W. Jaworowicz, D. Shepard, A. Shahzamani, A. J. Jones and S. D. Putney, Nat. Med., 1996, 2, 795-799.

9 H. K. Kim, H. J. Chung and T. G. Park, J. Controlled Release, 2006, 112, 167-174.

10 G. Wei, L. F. Lu and W. Y. Lu, Int. J. Pharm., 2007, 338, 125-132. 11 F. W. Okumu, N. Dao le, P. J. Fielder, N. Dybdal, D. Brooks, S. Sane and J. L. Cleland, Biomaterials, 2002, 23, 4353-4358.
12 J. Garcia, M. J. Dorta, O. Munguia, M. Llabres and J. B. Farina, Biomaterials, 2002, 23, 4759-4764.

13 V. R. Sinha and A. Trehan, J. Controlled Release, 2003, 90, 261-280.

14 J. A. Yang, E. S. Kim, J. H. Kwon, H. Kim, J. H. Shin, S. H. Yun, K. Y. Choi and S. K. Hahn, Biomaterials, 2012, 33, 5947-5954.

15 H. R. Mott and I. D. Campbell, Curr. Opin. Struct. Biol., 1995, 5, 114-121.

16 Y. Nagatomi, M. Ikeda, H. Uchida, M. Wada, H. Kobayashi, Y. Hashimoto, K. Mabuchi, M. Hayakawa, N. Kusuhara and M. Honjo, Growth Horm. IGF Res., 2000, 10, 207-214.

17 E. N. Lee, Y. M. Kim, H. J. Lee, S. W. Park, H. Y. Jung, J. M. Lee, Y. H. Ahn and J. Kim, Pharm. Res., 2005, 22, 1735-1746.

18 F. Kratz, J. Controlled Release, 2008, 132, 171-183.

19 E. T. Harvill, J. M. Fleming and S. L. Morrison, J. Immunol., 1996, 157, 3165-3170.

20 S. J. Im, S. I. Yang, S. H. Yang, D. H. Choi, S. Y. Choi, H. S. Kim, D. S. Jang, K. S. Jin, Y. K. Chung, S. H. Kim, S. H. Paik, Y. C. Park, M. K. Chung, Y. B. Kim, K. H. Han, K. Y. Choi and Y. C. Sung, PLoS One, 2011, 6, e24574.

21 C. A. Janeway, P. Travers, M. Walport and M. Shlomchik, Immunology: The Immune System in Health and Disease, Garland Science Publishing, New York, 2005.

22 L. G. Presta, J. Allergy Clin. Immunol., 2005, 116, 731-736; quiz 737.

23 S. P. Adiga, C. Jin, L. A. Curtiss, N. A. Monteiro-Riviere and R. J. Narayan, Wiley Interdiscip. Rev.: Nanomed. Nanobiotechnol., 2009, 1, 568-581.

24 E. A. Jackson and M. A. Hillmyer, ACS Nano, 2010, 4, 35483553.

25 J. K. Kim, S. Y. Yang, Y. Lee and Y. Kim, Prog. Polym. Sci., 2010, 35, 1325-1349.

26 S. Y. Yang, I. Ryu, H. Y. Kim, J. K. Kim, S. K. Jang and T. P. Russell, Adv. Mater., 2006, 18, 709-712.

27 S. Y. Yang, J. A. Yang, E. S. Kim, G. Jeon, E. J. Oh, K. Y. Choi, S. K. Hahn and J. K. Kim, ACS Nano, 2010, 4, 3817-3822.

28 S. Y. Yang, S. Son, S. Jang, H. Kim, G. Jeon, W. J. Kim and J. K. Kim, Nano Lett., 2011, 11, 1032-1035.

29 O. Glatter and O. Kratky, Small Angle X-ray Scattering, Academic Press, London, 1982.

30 S. M. Kelly, T. J. Jess and N. C. Price, Biochim. Biophys. Acta, Proteins Proteomics, 2005, 1751, 119-139.

31 B. C. Cunningham, M. G. Mulkerrin and J. A. Wells, Science, 1991, 253, 545-548.

32 G. Dienys, J. Sereikaite, V. Luksa, O. Jarutiene, E. Mistiniene and V. A. Bumelis, Bioconjugate Chem., 2000, 11, 646-651.

33 Y. F. Maa and C. C. Hsu, J. Pharm. Sci., 1998, 87, 808-812.

34 C. Lutz, M. Kollmann and C. Bechinger, Phys. Rev. Lett., 2004, 93, 625-627.

35 J. Sane, J. T. Padding and A. A. Louis, Faraday Discuss., 2010, 144, 285-299.

36 J. C. Kang and S. P. Schwendeman, Mol. Pharmaceutics, 2007, 4, 104-118.

37 L. S. Argetsinger, G. S. Campbell, X. Yang, B. A. Witthuhn, O. Silvennoinen, J. N. Ihle and C. Carter-Su, Cell, 1993, 74, 237-244.

38 J. M. Haugh, Biotechnol. Prog., 2004, 20, 1337-1344. 